\title{
Badania zróżnicowania składu chemicznego Cr spineli w obrębie masywu skał ultramaficznych na przykładzie SE Kosowa - zastosowanie w poszukiwaniach zlóż i wzbogacaniu rud chromu
}

\author{
Magdalena Ożóg ${ }^{1}$, Jadwiga Pieczonka ${ }^{1}$, Adam Piestrzyński ${ }^{1}$, Tomasz Ćwiertnia ${ }^{1}$
}

\begin{abstract}
Study on diversity of Cr spinel composition within the ultramafic massif based on the example of SE Kosovo - implications for chromium deposit exploration and beneficiation. Prz. Geol. 67: 186-188; doi: 10.7306/2019.16

A b s t r a c t. New data on chemistry of Cr spinels hosted within the ultramafic massif located in SE Kosovo show variations in their primary composition, which depends on ore and rock types. Spinels form disseminated and vein type ores and accessory spinels in peridotites are characterized by lower $\mathrm{Cr}$ and higher Fe concentrations in comparison to spinels making up massive ores. Concentrations of these metals increase in altered spinels both in ores and peridotites. Contents of Mn and Zn tend to be higher in accessory spinels than in spinels occurring in ores. The lower Cr:Fe ratio for Cr-rich spinels in disseminated ores in relations to chromite in massive ores may have an influence on their industrial usefulness. The use of EPMA-WDS technique for detrital spinels should be considered as an effective tool for chromium deposit exploration, especially in greenfield projects, to assess an ultramafic massif potential for hosting rich ores. Chemical analyses of spinels are recommended in planning a beneficiation process for the low-grade chromite ores, in order to obtain high quality concentrates.
\end{abstract}

Keywords: chromite, spinels, ophiolite, Kosovo, EPMA

Do spineli najważniejszych ze względu na znaczenie ekonomiczne należy chromit, który jako jedyny minerał jest źródłem $\mathrm{Cr}$, niezbędnego dla przemysłu metalurgicznego, odlewniczego i chemicznego. Skład chemiczny spineli chromowych, które stanowią roztwór stały, jest uzależniony od wymiany jonów metali z otaczającymi go krzemianami, w procesie tworzenia równowagi podczas krzepnięcia magmy (Roeder, Campbell, 1985), może także zostać zmieniony w czasie serpentynizacji i metamorfizmu, jak dowiedziono licznymi badaniami (np. González-Jiménez i in., 2009; Delura, 2012). Od chemizmu rudy chromitowej zależy jej ostateczne przeznaczenie gospodarcze, a do najistotniejszych wskaźników przydatności należy stosunek zawartości chromu do żelaza $(\mathrm{Cr}: \mathrm{Fe})$. Najbardziej pożądane są chromity o wartości tego stosunku równej lub zbliżonej $3: 1$, które stanowią dodatek stopowy podczas wytwarzania stali nierdzewnych. Ze względu na małą dostępność złóż wysokojakościowych rud podejmowane są próby wzbogacania rud ubogich, których skład mineralny i chemiczny odbiegają od składu rud masywnych.

$\mathrm{W}$ ramach badań analizie został poddany skład chemiczny spineli pochodzących z chromonośnego masywu ultramaficznego położonego na SSW od miejscowości Kačanic, przy granicy kosowsko-macedońskiej. Obszar badań znajduje się w obrębie pasa ofiolitowego Mirdita, który ma swoją kontynuację w Albanii (jurajsko-kredowy ofiolit strefy Pindos, powstały po zamknięciu oceanu Tetydy) (Dilek, Furnes, 2009). Punktowe analizy składu pierwiastkowego zostały wykonane techniką EPMA-WDS (przy użyciu długości fali wtórnego promieniowania X) w Laboratorium Pierwiastków Krytycznych AGH-KGHM (mikrosonda elektronowa JEOL SuperProbe JXA-8230) w mikroobszarach próbek rudy chromitowej oraz próbek szlichowych, uzyskanych z materiału deluwialnego rozwiniętego na harzburgitach i dunitach, a także $z$ aluwiów jednej $\mathrm{z}$ głównych dolin rozwiniętych w obszarze badań (spinele detrytyczne).
Celem pracy było określenie różnic w składzie chromitu tworzącego rudę masywną ( $\geq 80 \%$ obj. chromitu), żyłową (żyłki chromitowe o miąższości do kilku cm) i rozproszoną ( $\leq 30 \%$ obj. chromitu), a także zbadanie składu spineli wchodzących w skład dunitu i harzburgitu oraz materiału aluwialnego (spinele stanowiące składnik akcesoryczny perydotytów, spinele detrytyczne w szlichach), pobranych w obrębie wskazanego masywu ultramaficznego w Kosowie. Zwrócono uwagę na możliwość zastosowania informacji o ich składzie w poszukiwaniach złóż rud chromu oraz na kwestię wykorzystania ubogich rud chromitowych do produkcji żelazochromu.

\section{WYNIKI BADAŃ}

Pierwotny i zmieniony skład chemiczny spineli w rudzie odpowiada składowi magnesiochromitu oraz chromitu (ryc. 1). Ich chemizm jest uzależniony od typu teksturalnego rudy. Zawartość $\mathrm{Cr}_{2} \mathrm{O}_{3}$ (\% wag.) w niezmienionym chromicie tworzącym rudę mieści się $\mathrm{w}$ przedziale od 54,83 (dla rudy żyłowej) do 63,15 (dla rudy masywnej). Rudy żyłowa i rozproszona $\mathrm{w}$ porównaniu $\mathrm{z}$ rudą masywną, charakteryzują się wyższą zawartością żelaza zarówno $\mathrm{Fe}^{2+}$, jak i Fe ${ }^{3+}$. Dla rudy masywnej sa to zawartości $\mathrm{FeO}$ i $\mathrm{Fe}_{2} \mathrm{O}_{3}$ (\% wag.) wynoszące odpowiednio 14,49 i 2,85, dla żyłowej - 18,69 i 3,74, a dla rozproszonej-18,52 i 3,15. Chromit w rudzie masywnej posiada najwyższy średni stosunek $\mathrm{Cr}$ do $\mathrm{Fe}(\%$ at.) równy 3,27 , podczas gdy dla rudy żyłowej jego wartość wynosi 2,38, a dla rozproszonej-2,54 (ryc. 2). Najniższą średnią zawartość Al i Mg zaobserwowano w rudzie rozproszonej $\left(\mathrm{Al}_{2} \mathrm{O}_{3}-9,76 \%\right.$ wag.; $\mathrm{MgO}$ $-9,26 \%$ wag. $)$, a najwyższe w rudzie masywnej $\left(\mathrm{Al}_{2} \mathrm{O}_{3}\right.$ - 9,95\% wag.; 11,99\% wag. $\mathrm{MgO}$ ). $\mathrm{Na}$ uwage zasługuja różnice w zakresach zawartości Mn, V i Zn w rudach rozproszonej i masywnej (odpowiednio przedziały zawartości $0,22-0,40$ i $0,18-0,35 \%$ wag. $\mathrm{MnO} ; 0,15-0,24$ i $0,06-$ $0,24 \%$ wag. $\mathrm{V}_{2} \mathrm{O}_{3}, 0,11-0,17$ i $0,12-0,15 \%$ wag. $\left.\mathrm{ZnO}\right)$.

\footnotetext{
${ }^{1}$ AGH Akademia Górniczo-Hutnicza, Wydział Geologii, Geofizyki i Ochrony Środowiska, al. Mickiewicza 30, 30-059 Kraków; ozogm@agh.edu.pl;.jpieczon@geol.agh.edu.pl,piestrz@geol.agh.edu.pl,tcwiertnia@geol.agh.edu.pl
} 


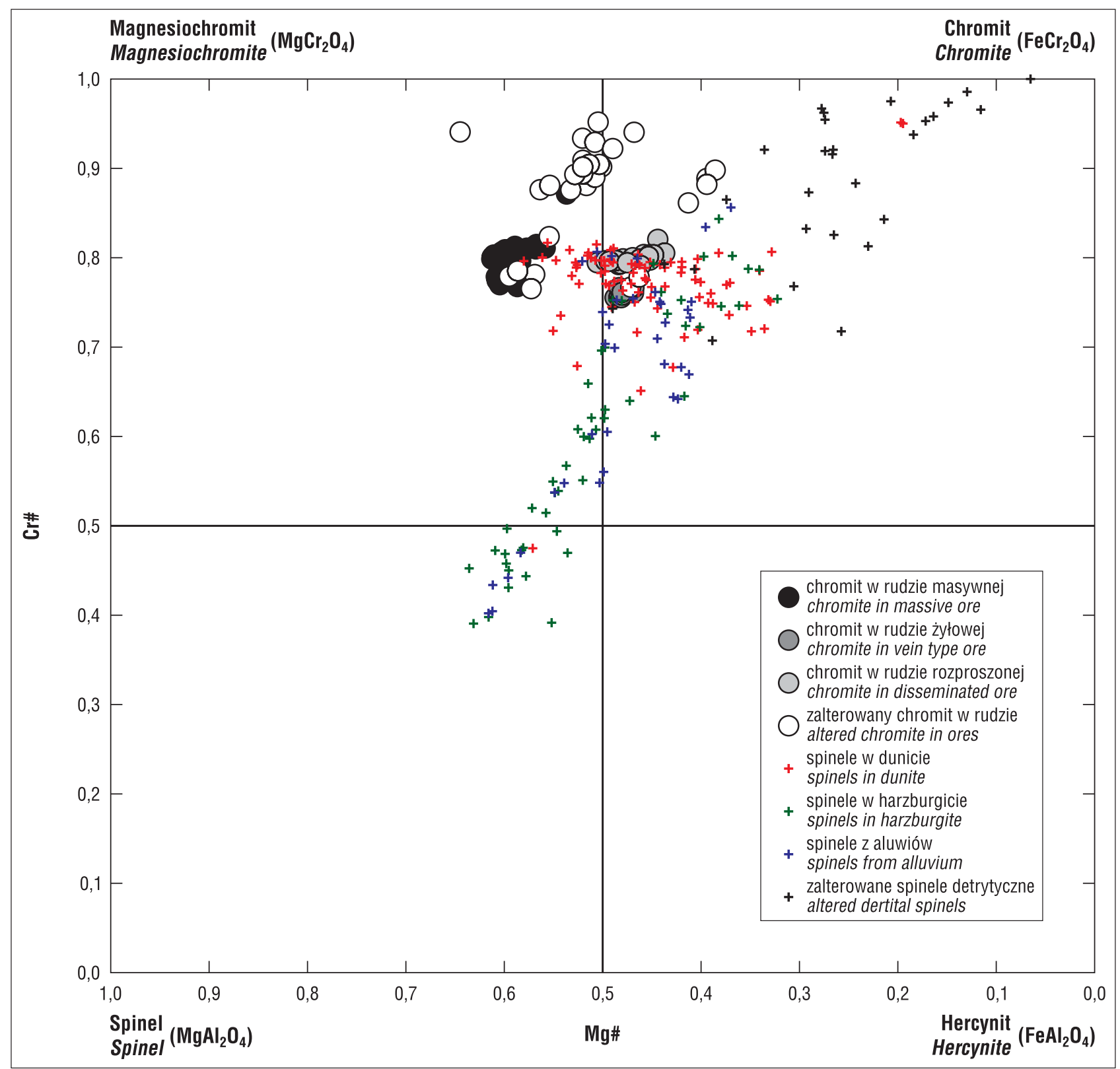

Ryc. 1. Zróżnicowanie składu spineli występujących w obszarze badań (klasyfikacja na podstawie wartości stosunku kationów $\mathrm{Mg} \#\left[\mathrm{Mg} /\left(\mathrm{Mg}+\mathrm{Fe}^{2+}\right)\right]$ vs. $\left.\mathrm{Cr} \#[\mathrm{Cr} /(\mathrm{Cr}+\mathrm{Al})]\right)$

Fig. 1. Diversity of spinels occurring within the study area (classification on the ground of ionic ratios: $\mathrm{Mg} \#\left[\mathrm{Mg} /\left(\mathrm{Mg}+\mathrm{Fe} e^{2+}\right)\right] v s$. $\mathrm{Cr} \#[\mathrm{Cr} /(\mathrm{Cr}+\mathrm{Al})])$

Zakres zawartości Cr w spinelach wchodzących w skład perydotytów (dunitu i harzburgitu) jest znacznie szerszy od zakresu zawartości tego metalu w rudzie (ryc. 2). Dla spineli pochodzących z wietrzenia dunitu średnia zawartość $\mathrm{Cr}_{2} \mathrm{O}_{3}$ (\%wag.) wynosi 55,26, a dla spineli pochodzących $\mathrm{z}$ wietrzenia harzburgitu zaledwie 46,30. W składzie mineralnym dunitów pojawia się spinel o typowym składzie chromitu, zbliżonym do składu chromitu tworzącego rudę, natomiast skład większości analizowanych spineli z harzburgitu widocznie odbiega od składu spineli występujących w dunicie i rudzie (ryc. 1). Dla harzburgitu charakterystyczna jest niemal dwukrotnie wyższa średnia zawartość $\mathrm{Al}$ w spinelach $\left(20,70 \%\right.$ wag. $\left.\mathrm{Al}_{2} \mathrm{O}_{3}\right)$ niż w przypadku dunitu $\left(10,93 \%\right.$ wag. $\left.\mathrm{Al}_{2} \mathrm{O}_{3}\right)$ i pojawienie się dodatkowo faz mineralnych o składzie zbliżonym do wzorcowego spinelu (ryc. 1). Wyraźna różnica w składzie spineli z perydotytów a spineli tworzących rudę dotyczy zawartości Mn, Zn i V. Spinele akcesoryczne zarówno w dunicie, jak i w harzburgicie charakteryzują się podwyższoną średnią zawartością Zn (do 0,19\% wag.), natomiast w samym dunicie zanotowano najwyższą zawartość Mn (śr. 0,37\% wag.) i najniższą V (śr. 0,06\% wag.). W materiale aluwialnym znalazły się spinele o składzie odpowiadającym tym, które znaleziono zarówno w rudzie, jak i perydotytach (materiał mieszany z całego masywu) (ryc. 1, 2).

Wyraźnie zauważalny jest wzrost zawartości $\mathrm{Cr}$ we wszystkich spinelach zalterowanych zarówno w chromicie tworzącym rudę, jak i w spinelach detrytycznych ze skał (ryc. 2). Zawartość $\mathrm{Cr}_{2} \mathrm{O}_{3}$ w przeobrażonym chromicie tworzacym rudzę dochodzi do $65,28 \%$ wag., a w przypadku spineli chromowych w perydotytach do $62,81 \%$ wag. Równocześnie ze wzrostem zawartości $\mathrm{Cr}$ następuje wzrost zawartości Fe (zakresy zawartości $\mathrm{FeO}$ i $\mathrm{Fe}_{2} \mathrm{O}_{3}$ $\mathrm{w} \%$ wag. $\mathrm{w}$ spinelach zmienionych $\mathrm{w}$ rudzie wynoszą odpowiednio 12,31-21,01 i 0,20-8,45, a w szlichach 18,05-29,05 i 2,46-59,41). Należy podkreślić, że zmiana 


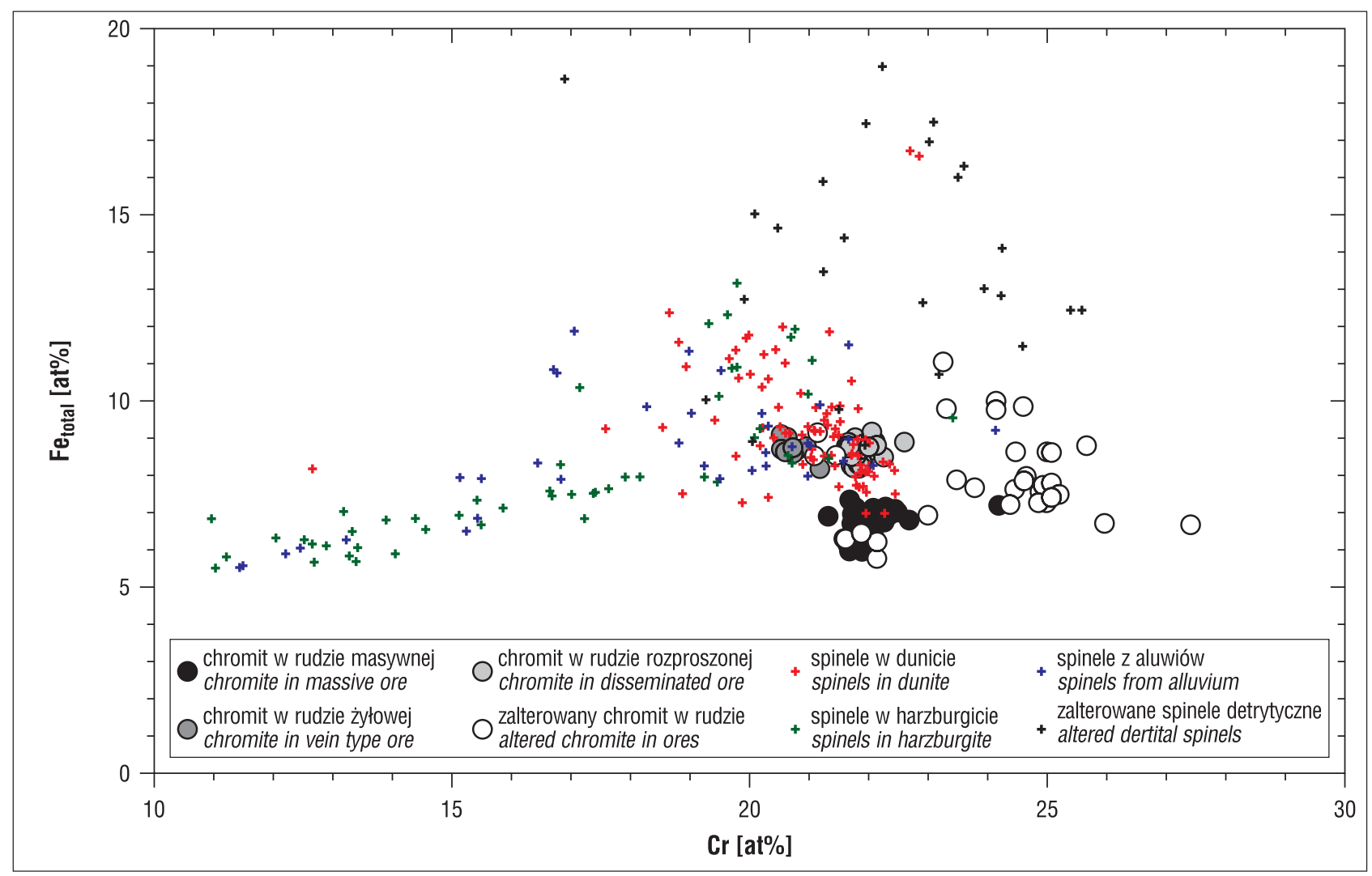

Ryc. 2. Porównanie stosunków zawartości $\mathrm{Cr}$ i Fe (suma $\mathrm{Fe}^{2+}$ i $\mathrm{Fe}^{3+}$ ) w składzie pierwotnym i zmienionym chromitu tworzącego rudy oraz detrytycznych spineli pochodzących z wietrzenia dunitu i harzburgitu oraz materiału aluwialnego występujących w obszarze badań Fig. 2. The comparion of $\mathrm{Cr}$ and $\mathrm{Fe}\left(\right.$ sum of $\mathrm{Fe}^{2+} \mathrm{i} \mathrm{Fe}{ }^{3+}$ ) contents in primary and altered chromites composing ores and detrital spinels from weathered dunite, harzburgite and alluvial material of the study area

składu dotyczy najczęściej zewnętrznych partii kryształów lub stref przy istniejących w nich spękaniach. W wielu przypadkach wyniki wskazują również na nieco podwyższoną zawartość Zn i Mn w strefach przeobrażeń spineli, względem ich składu pierwotnego.

Ziarna spineli, które znalazły się we frakcji magnetycznej szlichów (po ich ręcznej separacji przy użyciu magnesu), charakteryzują się wyższą o średnio $2,26 \%$ wag. zawartością żelaza (suma $\mathrm{FeO}$ i $\mathrm{Fe}_{2} \mathrm{O}_{3}$ ) od tych, które znalazły się we frakcji niemagnetycznej. Ponadto jest w nich także mniej $\mathrm{Cr}_{2} \mathrm{O}_{3}$ (średnio o $1,44 \%$ wag.), a stosunek $\mathrm{Cr}$ : Fe wynosi odpowiednio dla frakcji magnetycznej 2,36, a dla niemagnetycznej 2,11 (\% at).

\section{WNIOSKI}

Analizy typu EPMA-WDS pozwoliły na stwierdzenie wyraźnych różnic w składzie spineli wchodzących w skład rud oraz stanowiących składnik akcesoryczny skał ultramaficznych. W porównaniu do wysokojakościowej rudy masywnej zawartość Cr jest niższa, a Fe wyższa w spinelach występujących w rudzie żyłowej i rozproszonej oraz w perydotytach. Zaobserwowano również wyższą zawartość Mn, Zn i częściowo V w przypadku rudy rozproszonej i w spinelach akcesorycznych. Można wnioskować, że badanie składu spineli detrytycznych w szlichach pozwala na wstępne określenie perspektywiczności masywu ultramaficznego pod względem występowania rud o jakości odpowiedniej dla przemysłu. Stosowanie analiz typu EPMA dla spineli detrytycznych można uznać za przydatne narzędzie w prospekcji złożowej, do stosowania na wstępnych etapach poszukiwań złóż chromu, szczególnie w tzw. green field projects i na terenach trudno dostępnych, gdzie obecność wychodni jest ograniczona. Wyniki wskazują na wyraźnie mniej korzystny stosunek $\mathrm{Cr}$ do $\mathrm{Fe}$ w rudzie rozproszonej i żyłowej niż w rudzie masywnej, co bez wątpienia wpłynie na pogorszenie jakości uzyskanych $\mathrm{z}$ nich koncentratów, w stosunku do jakości koncentratów uzyskiwanych z bogatej rudy, a przez to możliwość użycia ich do produkcji żelazochromu. Zaobserwowana zmiana właściwości magnetycznych spineli w zależności od zawartości Fe i wartości Cr : Fe sugeruje zachowanie ostrożności przy doborze procesów przeróbki i dostosowanie ich do składu chemicznego wzbogacanej rudy (szczególnie jeśli spinele uległy alteracji), w celu uzyskania wysokojakościowych koncentratów.

Badania zostały sfinansowane z grantu dziekańskiego o numerze 15.11.140.016. Autorzy składają podziękowania firmie Proxis Sp. z o.o. za udostępnienie próbek do badań oraz mgr inż. Gabrieli Kozub-Budzyń za wykonanie analiz EPMA.

\section{LITERATURA}

DELURA K. 2012 - Chromitites from the Sudetic ophiolite: origin and alteration. Wydaw. UW, Warszawa.

DILEK Y., FURNES H. 2009 - Structure and geochemistry of Tethyan ophiolites and their petrogenesis in subduction rollback systems. Lithos, 113: $1-20$.

GONZÁLEZ-JIMÉNEZ J.M., KERESTEDJIAN T., PROENZA J.A., GERVILLA F. 2009 - Metamorphism on chromite ores from the Dobromirtsi ultramafic massif, Rhodope Mountains (SE Bulgaria). Geol. Acta, 7 (4): 413-429.

ROEDER P.L., CAMPBELL I.H. 1985 - The effect of postcumulus reactions on composition of olivine-spinels from the Jimberlana. J. Petrol., 26 (3): 763-786. 